\title{
NNI Project Component Areas
}

National Cancer Institute

\section{Source}

National Cancer Institute. NNI Project Component Areas. NCI Thesaurus. Code C53669.

Program Component Areas are major subject areas under which related National Nanotechnology Initiative projects and activities are grouped. 